Journal of Animal and Veterinary Advances 11 (12): 2097-2105, 2012

ISSN: $1680-5593$

(C) Medwell Journals, 2012

\title{
Mini-Monovision with Multifocal PresbyLASIK for Myopic Presbyopes
}

\author{
Xiao-Xiong Wang, Yi-Qiao Xing and Xiao-Jiao Liu \\ Department of Ophthalmology, Renmin Hospital of Wuhan University, 430060 Wuhan, China
}

\begin{abstract}
To evaluate the outcomes of mini-monovision peripheral presbyLASIK in presbyopic myopes. Twenty eight subjects ( 56 eyes) were included in this prospective study. The mean age of the cohort was 51 years (range, 45-62 years). Mean Spherical Equivalent refraction (SE) of the dominant eyes was $-7.00 \pm 2.04 \mathrm{D}$ (range, -11.00 to $-4.00 \mathrm{D}$ ) and $-7.11 \pm 1.99 \mathrm{D}$ (range, -11.13 to $-4.25 \mathrm{D}$ ) for non-dominant eyes. Mini-monovision peripheral presbyLASIK was performed with the dominant eye corrected for distance vision and the nondominant eye for near vision using the NIDEK EC-5000 CX $\alpha$ excimer laser. The target refraction was $-0.25 \mathrm{D}$ for the dominant eyes and $-0.75 \mathrm{D}$ for the non-dominant eyes. Data are reported for the last postoperative visit ( 6 months or later). The mean postoperative $\mathrm{SE}$ was $-0.58 \pm 0.45 \mathrm{D}$ (range, -1.38 to $+0.50 \mathrm{D}$ ) with $71 \%$ within $\pm 0.50 \mathrm{D}$ of the intended SE for the dominant eyes. In the non-dominant eyes, mean postoperative SE was $-1.00 \pm 0.44 \mathrm{D}$ (range, -1.75 to $0 \mathrm{D}$ ) with $71 \%$ within $\pm 0.50 \mathrm{D}$ of the intended SE. All subjects achieved binocular Uncorrected Distance Visual Acuity (UDVA) of 0.8 or better, $82 \%$ achieved binocular Uncorrected near Visual Acuity (UNVA) of 0.8 or better and $93 \%$ achieved 0.5 or better. No eyes lost more than one line of BCVA and there were no serious complications after surgery. Mini-monovision peripheral presbyLASIK was safe, effective and highly predictable for myopic presbyopes.
\end{abstract}

Key words: Mini-monovision, refraction, dominant eye, binocular, complication

\section{INTRODUCTION}

Presbyopia or the loss of accommodation with age affects a significant proportion of the world's population. Hence, the demand for the treatment of presbyopia is considerable. Treatment for presbyopia involves two general choices, spectacles or surgery. Laser In situ Keratomileusis (LASIK) is a successful approach for the management of presbyopia using either monovision or multifocal corneal ablation (presbyLASIK) (Mantry and Shah, 2004).

Monovision correction leaves one eye with residual myopia for near vision. For example, one eye is fully corrected for distance vision and the other eye remains myopic with approximately $1.25-2.50 \mathrm{D}$ for near vision (Cox and Krueger, 2006). Patients who can tolerate this level of anisometropia, report a high degree of satisfaction with monovision (Cox and Krueger, 2006; Goldberg, 2003; Miranda and Krueger, 2004; Reilly et al., 2006). However, some patients experience decreased stereopsis and have difficulty with night driving after monovision correction (Cox and Krueger, 2006; Goldberg, 2003; Miranda and Krueger, 2004; Reilly et al., 2006).

Multifocal corneal ablation is a procedure based on multistep and multizone laser ablation that creates a progressive multifocal cornea that results in pseudoaccommodation (Telandro and Steile, 2006). Previous studies of multifocal corneal ablation or presbyLASIK have reported safety and efficacy of this ablation profile (Wang et al., 2007; Telandro, 2004; Cantu et al., 2004, 2005; Alio et al., 2006). In the experience with peripheral presbyLASIK, researchers found that some patients with minor anisometropia had better postoperative efficacy because their vision of both eyes would compensate for each other and the patients seemed satisfied. Based on these observations, researchers designed a study to evaluate the safety, predictability and efficacy of a mini-monovision (Reinstein et al., 2011) peripheral presbyLASIK (Telandro and Steile, 2006; Telandro, 2004) treatments. The mini-monovision peripheral presbyLASIK treatment is a bilateral multifocal ablation with the dominant eye corrected for distance vision and the non-dominant eye for near vision.

\section{MATERIALS AND METHODS}

Study design: This study was a prospective, noncomparative clinical study. All subjects underwent an informed consent procedure and were required to sign a consent document prior to surgery. This study conformed to the tenets of the Declaration of Helsinki and the study

Corresponding Author: Xiao-Xiong Wang, Department of Ophthalmology, Renmin Hospital of Wuhan University, 430060 Wuhan, China 
was approved by the Human Studies Review Board of Wuhan University, Wuhan, China. Surgeries were performed from June 2006 to December 2007.

Subjects and examination: To be included in the study, subjects had to be 45-65 years of age with at least -4.00D myopia and cylinder no greater than $-5.50 \mathrm{D}$, Corrected Distance Visual Acuity (CDVA) of each eye $\geq 0.8$ (decimal notation) and medically suitable for LASIK and free of corneal or retinal disease that would preclude LASIK. Subjects who listed driver as their main occupation were excluded.

The preoperative examinations for all subjects included measurement of Uncorrected Distance Visual Acuity (UDVA), CDVA, manifest refraction, slit-lamp examination, funduscopic examination, combined corneal topography, aberrometry (6 $\mathrm{mm}$ pupil diameter, 8th Zernike order) and pupillometry (OPD-Scan, Nidek Co., Ltd. Gamagori, Japan), intraocular pressure (TX-F Full Auto Tonometer, Canon Inc., Tokyo, Japan), accommodative amplitude, contrast sensitivity (Functional Acuity Contrast Test, Stereo Optical Co., Inc., Chicago, Il, USA), ocular dominance testing (Miranda and Krueger, 2004) and ultrasound pachymetry (UP-1000 Ultrasonic Pachymeter, Nidek Co., Ltd. Gamagori, Japan).

UDVA and CDVA were tested using the decimal scale distance visual acuity chart. Near visual acuity was tested at $40 \mathrm{~cm}$ using the decimal scale near visual acuity chart. Uncorrected visual acuity was tested binocularly and monocularly whereas CDVA was tested monocularly only. Ocular dominance was tested with the subject binocularly aligning a distant object through a hole in a card while keeping still and alternately closing one eye then the other. The eye with which the subject could see the object through the hole was deemed the dominant eye.

The subjective minus to Blur Method (Ostrin and Glasser, 2004) was used to measure accommodative amplitude. The subject wore distance correction based on the manifest refraction and focused on the line above the CDVA line of the decimal scale distance visual acuity chart at $5 \mathrm{~m}$ with one eye while the other eye was occluded. Minus lens power was added in front of the eye in $0.25 \mathrm{D}$ increments until the subject reported the line could no longer be held in clear focus. The minus-lens power added over distance correction was recorded as the accommodative amplitude.

Postoperative examinations were performed at 1 day and 10 days and 1, 3,6 and 12 months. Postoperative examinations included measurement of monocular and binocular uncorrected visual acuity at both distance and near, slit-lamp examination and computerized corneal topography. Intraocular pressure measurements were performed at 1,3 and 6 months postoperatively. Measurement of manifest refraction, CDVA, accommodative amplitude and contrast sensitivity was performed at 6 and 12 months postoperatively.

A questionnaire was used to investigate the quality of distance and near visual acuity, the degree of the subject's satisfaction and dependence on glasses after surgery. The degree of satisfaction was rated by the subject as satisfactory, acceptable or unsatisfactory.

Surgical procedure: All surgeries were performed by the same experienced surgeon $(\mathrm{X}-\mathrm{xW})$. Bilateral LASIK surgery was performed in all subjects using the multifocal corneal ablation profile. Hinged corneal flaps were created with the Hansatome microkeratome (Bausch and Lomb Inc., Rochester, NY, USA) with an intended flap diameter of $8.5 \mathrm{~mm}$ and a flap thickness of $160 \mu \mathrm{m}$. The refractive ablation was performed with the EC-5000 CX $\alpha$ excimer laser platform (NIDEK Co., Ltd. Gamagori, Japan) with the manufacturer's nomogram.

The dominant eye was targeted for $-0.25 \mathrm{D}$ in all cases and the non-dominant eye was targeted for $-0.75 \mathrm{D}$. All corrections were based on preoperative manifest refraction. The profile was created using the multistep laser ablation as follows: the myopic sphere was corrected in 2 steps; first the spherical value $(-2.75 \mathrm{D}$ was subtracted from the manifest sphere in the dominant eye and $-3.25 \mathrm{D}$ was subtracted from the manifest sphere in the nondominant eye) was corrected at $6 / 7 \mathrm{~mm}$ Optical Zone/Transition Zone (OZ/TZ). The second step was the correction of $-2.50 \mathrm{D}$ at $3-3.5 / 4-5 \mathrm{~mm} \mathrm{OZ} / \mathrm{TZ}$. The cylinder was fully corrected with a $6 \mathrm{~mm} \mathrm{OZ}$ and $7 \mathrm{~mm} \mathrm{TZ}$ in all cases.

Sample laser data entry for a subject with manifest refraction of $-6.00-2 \times 180$ OD (dominant eye) and $-6.50-2 \times 165$ OS are shown.

\section{Dominant eye:}

- Step 1: $-3.25-2.00 \times 1806 / 7 \mathrm{~mm}(\mathrm{OZ} / \mathrm{TZ})$

- $\quad$ Step 2: -2.50 sphere only $3.5 / 5 \mathrm{~mm}(\mathrm{OZ} / \mathrm{TZ})$

\section{Non dominant eye (OS):}

- $\quad$ Step 1: $-3.25-2.00 \times 1656 / 7 \mathrm{~mm}(\mathrm{OZ} / \mathrm{TZ})$

- Step 2: -2.50 sphere only 3/4 mm (OZ/TZ)

After surgery, subjects were instructed to instill antibiotic eye drops four times daily for the 1 st week fluorometholone $0.1 \%$ (Allergan Inc., Ireland) eye drops on a tapering dose of four times daily for the 1 st week, 
then three times daily for the next week, two times daily for the following week and once daily for an additional week. Artificial tears were instilled three times daily for 1 month postoperatively.

Data collection and analysis: Statistical analysis of the results was performed with SPSS1 1.0 for windows (SPSS, Chicago). Visual acuity data were converted to the logarithm of the minimum angle of resolution value for data analysis. The paired sample t-test was used to compare ocular (whole eye) spherical aberration and accommodative amplitude preoperatively and postoperatively. A nonparametric test (Wilcoxon signed rank test) was used to compare preoperative visual acuity to postoperative visual acuity and the change in contrast sensitivity from preoperatively to postoperatively. The difference was considered statistically significant when $\mathrm{p}<0.05$. Data at the last postoperative visit are reported.

\section{RESULTS AND DISCUSSION}

The study cohort was comprised of 28 subjects ( 6 men and 22 women, 56 eyes). Mean subject age was 51 years (range, 45-62 years). Preoperatively, the mean myopia was $-6.73 \pm 1.96 \mathrm{D}$ (range, -11.00 to $-4.00 \mathrm{D}$ ), mean cylinder was $-0.64 \pm 0.80 \mathrm{D}$ (range, $-5.50-0 \mathrm{D}$ ) and mean Spherical Equivalent refraction (SE) was $-7.05 \pm 2.00 \mathrm{D}$ (range, -11.13 to $-4.00 \mathrm{D}$ ). Pupil diameter was successfully measured on 26 subjects (52 eyes) preoperatively. The mean preoperative photopic pupil diameter was $3.53 \pm 0.42 \mathrm{~mm}$ (range, 2.63-4.24 mm) and the mesopic pupil diameter $5.61 \pm 0.87 \mathrm{~mm}$ (range, $3.12-7.37 \mathrm{~mm}$ ). Postoperatively, the pupil diameter was successfully measured on 26 subjects (52 eyes). The mean postoperative photopic pupil diameter was $3.46 \pm 0.44 \mathrm{~mm}$ (range, 2.54-4.22 $\mathrm{mm}$ ) and mean mesopic diameter was $5.52 \pm 0.89 \mathrm{~mm}$ (range, $3.84-7.46 \mathrm{~mm}$ ).

All 28 subjects (including one eye that underwent retreatment) completed a minimum follow up of 6 months. Mean follow-up was $8.14 \pm 2.51$ months (range, 6-13 months).

Efficacy: The preoperative UDVA of all eyes was $<0.2$. The postoperative monocular and binocular UDVA is shown in Fig. 1. The postoperative UDVA of all eyes increased. The number of eyes with UDVA of $1.0-1.5$ or better is shown in Table 1 .

The preoperative Uncorrected Near Visual Acuity (UNVA) for dominant eyes, non-dominant eyes and binocularly is shown in Fig. 2 and the postoperative UNVA is shown in Fig. 3. The postoperative UNVA of the
Table 1: Uncorrected Distance Visual Acuity (UDVA) after minimonovision peripheral presbyLASIK

\begin{tabular}{lccc}
\hline UDVA & $\begin{array}{c}\text { Dominant eyes } \\
(\mathrm{n}=28 \text { eyes })\end{array}$ & $\begin{array}{c}\text { Non-dominant eyes } \\
(\mathrm{n}=28 \text { eyes })\end{array}$ & $\begin{array}{c}\text { Binocular } \\
(\mathrm{n}=28 \text { subjects })\end{array}$ \\
$\geq 1.0$ & $16(57 \%)$ & $9(32 \%)$ & $20(71 \%)$ \\
$\geq 1.2$ & $9(32 \%)$ & $3(11 \%)$ & $13(46 \%)$ \\
$\geq 1.5$ & 0 & 0 & $1(4 \%)$ \\
\hline
\end{tabular}

$z$ : greater than or equal to

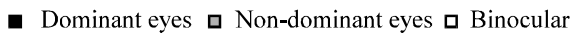

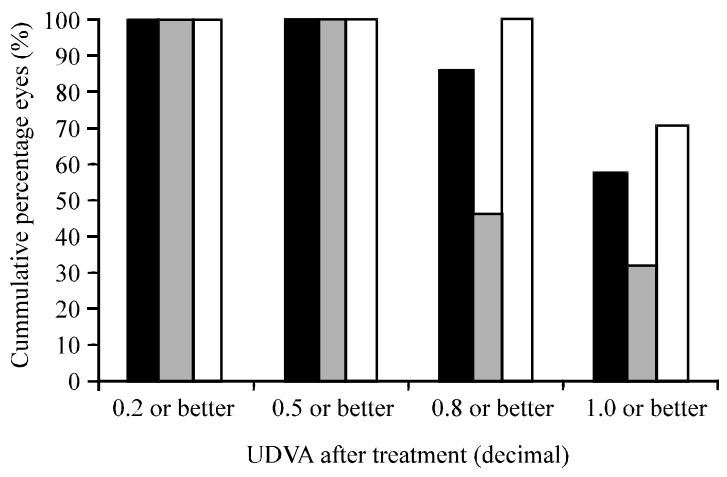

Fig. 1: Cumulative histogram for Uncorrected Distance Visual Acuity (UDVA) after mini-monovision peripheral presbyLASIK for myopia and presbyopia, grouped into dominant eyes $(100,100$, 86 and $57 \%)$, non-dominant eyes (100, 100, 46 and $32 \%)$ and binocularly $(100,100,100$ and $71 \%)$. Percentages are calculated for 28 dominant eyes, 28 non-dominant eyes of 28 subjects

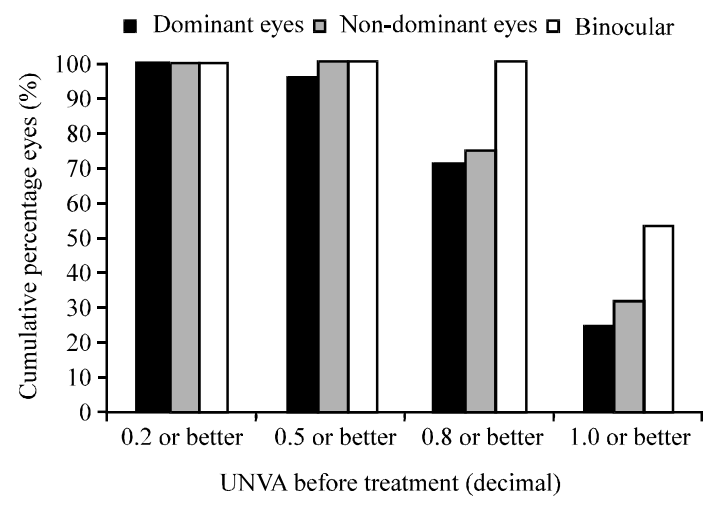

Fig. 2: Cumulative histogram for Uncorrected Near Visual Acuity (UNVA) before treatment, grouped into dominant eyes $(100,96,71$ and $25 \%)$, non-dominant eyes $(100,100,75$ and $32 \%)$ and binocularly (100, 100, 100 and 54\%). Percentages are calculated for 28 dominant eyes, 28 non-dominant eyes of 28 subjects

non-dominant eyes did not change significantly compared to preoperatively $(Z=-0.269, p=0.788)$ (Fig. 2 and 3$)$. The 
UNVA of dominant eyes and the binocular UNVA decreased statistically significantly compared to preoperatively $(Z=-2.673, p=0.008 ; Z=-2.145, p=0.032$, respectively) (Fig. 2 and 3 ).

The postoperative binocular UNVA of subjects with binocular UDVA $=0.8$ and $\geq 1.0$ is shown in Fig. 4. The postoperative binocular UNVA with the binocular UDVA $=0.8$ was 0.5 or better in $93 \%$ of subjects and 0.8 or better in $82 \%$ of subjects. After surgery, the binocular UDVA was better than the dominant eye UDVA $(Z=-3.500, p<0.001)$ and the binocular UNVA was better than the non-dominant eye UNVA $(Z=-3.317$, $\mathrm{p}=0.001)$.

Safety: Postoperatively, 4 eyes (7\%) lost 1 line of CDVA and none lost $>1$ line and 16 eyes (29\%) gained 1 line of CDVA. No intraoperative complications occurred during this study. Postoperatively, there were no serious complications such as infection, epithelium ingrowth, corneal ectasia and severe dry eye. The results of mean contrast sensitivity are shown in Fig. 5. No significant change occurred at $1.5,3,6,12$ cycles/degree $(Z=-1.225$, $-1.347,-1.000,-1.284 ; \mathrm{p}=0.221,0.178,0.317,0.199$,

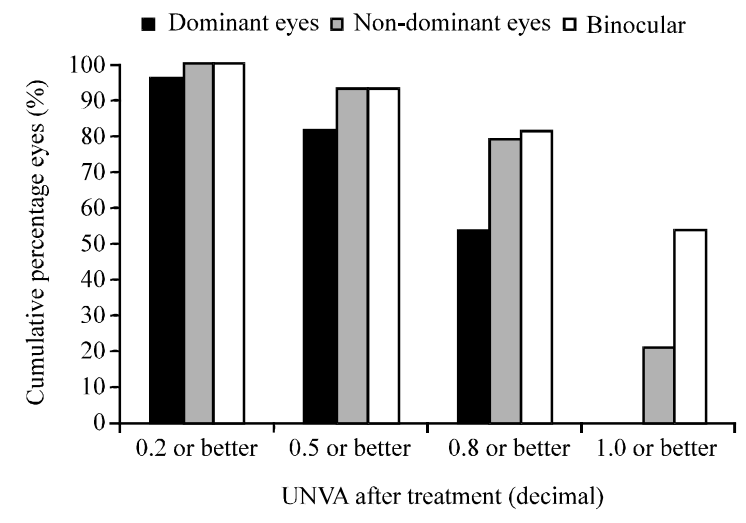

Fig. 3: Cumulative histogram for Uncorrected Near Visual Acuity (UNVA) after mini-monovision peripheral presbyLASIK for myopia and presbyopia, grouped into dominant eyes $(96,82,54$ and $0 \%)$, non-dominant eyes $(100,93,79$ and $21 \%)$ and binocularly $(100,93,82$ and $54 \%)$. Percentages are calculated for 28 dominant eyes, 28 non-dominant eyes and 28 subjects respectively). The contrast sensitivity at 18 cycles/degree decreased statistically significantly compared to preoperatively $(Z=-2.466 ; \mathrm{p}=0.014)$.

Predictability: Mean SE and mean cylindrical refraction before and after treatment are shown in Table 2 of the

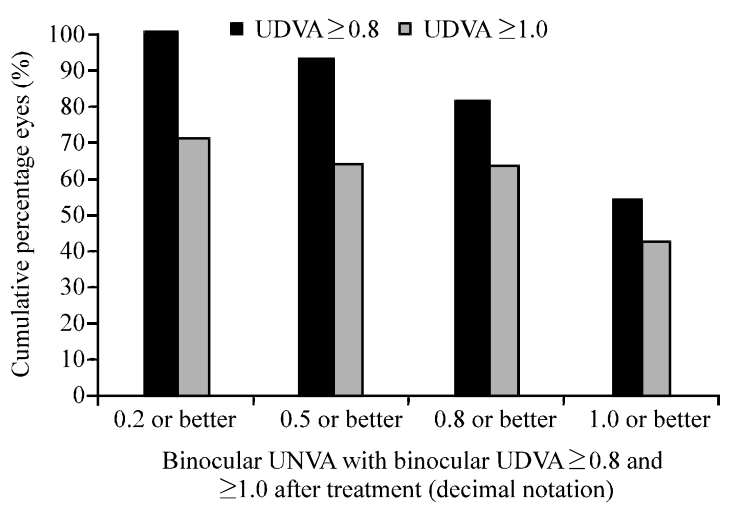

Fig. 4: Cumulative histogram for binocular Uncorrected Near Visual Acuity (UNVA) after mini-monovision peripheral presbyLASIK for myopia and presbyopia, grouped into binocular UNVA with binocular Uncorrected Distance Visual Acuity (UDVA) $\geq 0.8(100,93,82$ and $54 \%)$ and with binocular UDVA $\geq 1.0(71,64,64$ and $43 \%)$

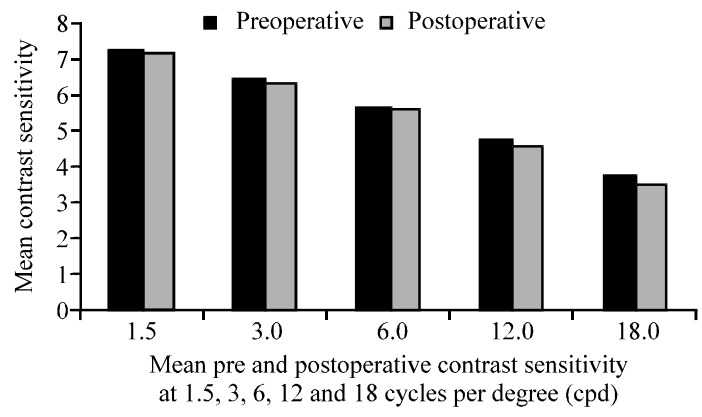

Fig. 5: Mean pre- and postoperative contrast sensitivity at $1.5,3,6,12$ and 18 cycles per degree (cpd) of eyes that underwent mini-monovision peripheral presbyLASIK for myopia and presbyopia. Preoperative $(7.27 \pm 0.77,6.46 \pm 0.71$, $5.68 \pm 0.54, \quad 4.77 \pm 0.91$ and $3.75 \pm 0.90)$ and Postoperative $(7.16 \pm 0.89,6.34 \pm 0.79,5.59 \pm 0.73$, $4.63 \pm 0.73$ and $3.48 \pm 0.63$ )

Table 2: Mean spherical equivalent refraction and mean cylindrical refraction before and after mini-monovision peripheral presbyLASIK

\begin{tabular}{|c|c|c|c|c|c|}
\hline \multirow[b]{2}{*}{ Eye pattem $(n=28)$} & \multicolumn{3}{|c|}{ Mean spherical equivalent refraction (D) } & \multicolumn{2}{|c|}{ Mean cy lindrical refraction (D) } \\
\hline & Preoperative & Target & Postoperative & Preoperative & Postoperative \\
\hline Dominant eyes & $\begin{array}{l}-7.00 \pm 2.04 \\
(-11.00 \text { to }-4.00)\end{array}$ & -0.25 & $\begin{array}{l}-0.58 \pm 0.45 \\
(-1.38 \text { to }+0.50)\end{array}$ & $\begin{array}{l}-0.64 \pm 1.06 \\
(-5.50 \text { to } 0)\end{array}$ & $\begin{array}{l}-0.20 \pm 0.28 \\
(-0.75 \text { to } 0)\end{array}$ \\
\hline Non-dominant ey es & $\begin{array}{l}-7.11 \pm 1.99 \\
(-11.13 \text { to }-4.25)\end{array}$ & -0.75 & $\begin{array}{l}-1.00 \pm 0.44 \\
(-1.75 \text { to } 0)\end{array}$ & $\begin{array}{l}-0.64 \pm 0.43 \\
(-1.50 \text { to } 0)\end{array}$ & $\begin{array}{l}-0.24 \pm 0.33 \\
(-1.00 \text { to } 0)\end{array}$ \\
\hline
\end{tabular}


dominant eyes, 20 eyes $(71 \%)$ were within $\pm 0.50 \mathrm{D}$ of the intended target and 27 eyes (96\%) were within $\pm 1.00 \mathrm{D}$. Of the non-dominant eyes, 20 eyes $(71 \%)$ were within $\pm 0.50 \mathrm{D}$ of intended target and 28 eyes $(100 \%)$ were within $\pm 1.00 \mathrm{D}$. Scatterplot of attempted versus achieved SE are shown in Fig. 6.

Spherical aberration: The spherical aberration changed from $-0.10 \pm 0.31 \mu \mathrm{m}$ (range, $-1.41-0.31 \mu \mathrm{m}$ ) preoperatively to $0.16 \pm 0.38 \mu \mathrm{m}$ (range, $-0.98-0.71 \mu \mathrm{m}$ ) postoperatively. The change in spherical aberration was statistically significant $(\mathrm{t}=-6.517, \mathrm{p}<0.001)$.

Accommodative amplitude: The accommodative amplitude increased from $1.58 \pm 0.53 \mathrm{D}$ (range, 0.50D-2.75D) preoperatively to $1.93 \pm 0.65 \mathrm{D}$ (range, $0.50 \mathrm{D}-3.00 \mathrm{D}$ ) postoperatively $(\mathrm{t}=-8.464, \mathrm{p}<0.001)$. Figure 7 plots mean accommodative amplitude preoperatively and postoperatively in age matched subjects.

Retreatments: The dominant eye of one patient underwent retreatment for distance vision and the etreatment rate was $2 \%$. After primary treatment, the spherical equivalent refraction of the patient's dominant eye was $-1.75 \mathrm{D}$ and the UDVA was 0.3 . After retreatment, the spherical equivalent refraction of the eye was $-0.75 \mathrm{D}$, and the UDVA was 1.0 .

Subjective survey: The need for distance glasses and reading glasses are shown in Fig. 8. All subjects reported that their postoperative UDVA was better thanpreoperatively. Three subjects $(11 \%)$ reported their

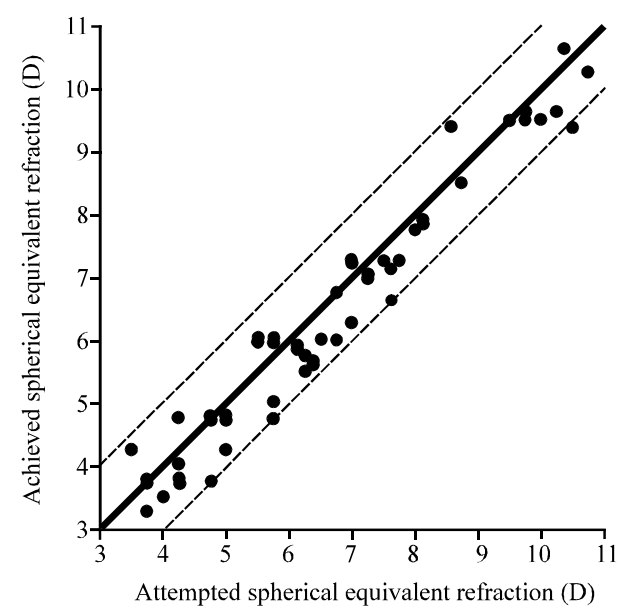

Fig. 6: Scatterplot of the attempted versus achieved spherical equivalent refraction after mini-monovision peripheral presbyLASIK for myopia and presbyopia postoperative UNVA was better, 10 subjects (36\%) reported that their postoperative UNVA was worse and 15 subjects $(54 \%)$ noticed no change in their postoperative UNVA. Twenty four subjects $(86 \%)$ were satisfied with the postoperative outcome, 3 subjects (11\%) reported the postoperative outcome was acceptable and 1 subject (4\%) was unsatisfied with the postoperative outcome.

Sample maps: Sample OPD maps and difference maps are shown in Fig. 9. The postoperative OPD map shows myopic power peripherally (Fig. 9). Sample topographic

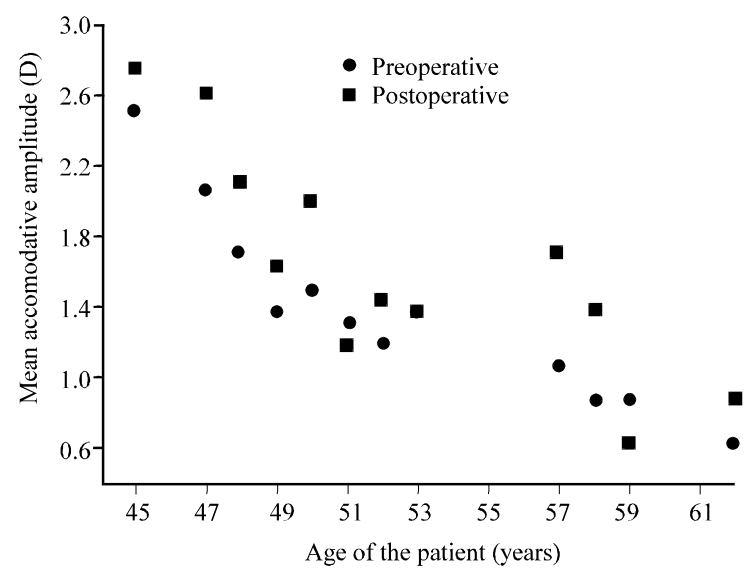

Fig. 7: Mean accommodative amplitude of all eyes matched for subjects who were the same age. All subjects underwent mini-monovision peripheral presbyLASIK for myopia and presbyopia

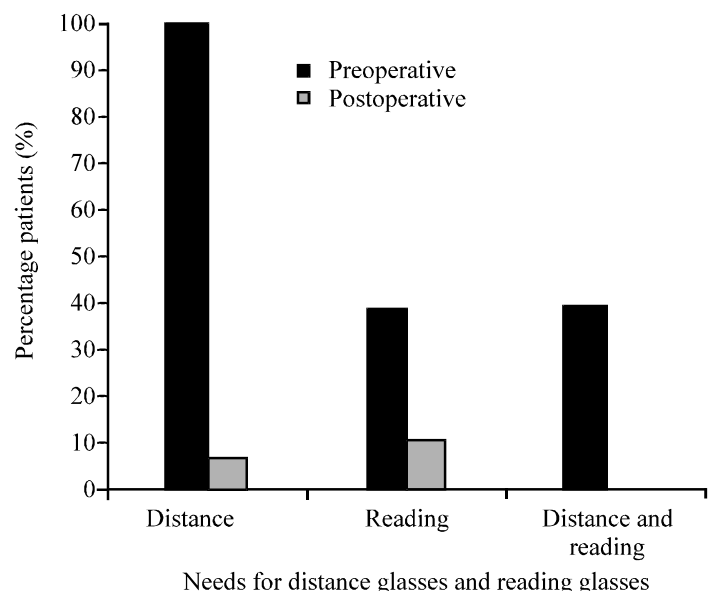

Fig. 8: The need for distance glasses and reading glasses before and after mini-monovision peripheral presbyLASIK for myopia and presbyopia. Preoperative $(100,39$ and 39\%), Postoperative $(7,11$ and $0 \%)$ 


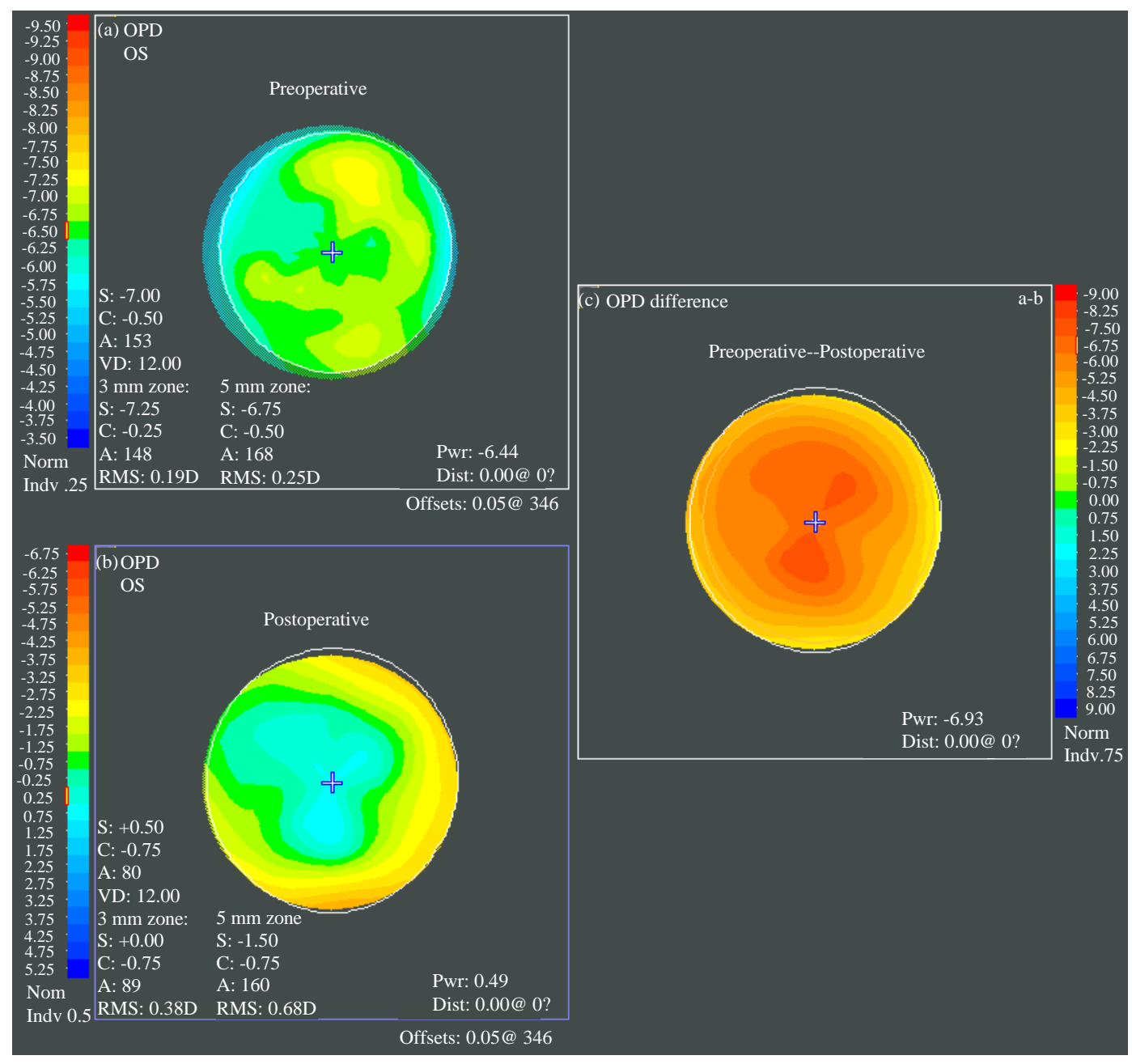

Fig. 9: Sample refractive aberrometry maps (optical path difference maps) preoperatively and postoperatively. The difference map indicates the difference between the preoperative and postoperative maps

and difference maps are shown in Fig. 10. Minimonovision peripheral presbyLASIK for presbyopia is based on two concepts. The first is the creation of pseudoaccommodation through multifocal corneal ablation (Telandro and Steile, 2006). The second is to make the vision of both eyes compensate for each other through asymmetric correction on both eyes. In the current study, this compensation was achieved as indicated by the postoperative binocular UDVA which was better than the dominant eye UDVA and the postoperative binocular UNVA which was better than the non-dominant eye UNVA.

As expected, the postoperative near vision should be adequate however there may be diminution in distance vision in a strategy that targets mild myopia. The results of the current study indicate that mini-monovision peripheral presbyLASIK was safe, effective and highly predictable for presbyopic myopes. Postoperatively, no eyes in the entire cohort lost 2 or more lines of CDVA. Although, the uncorrected near vision decreased, the majority of the subjects reported that their near vision was better or there was no change compared to preoperatively. This outcome was likely due to the improvement of intermediate distance vision. However, studies reporting intermediate vision data are required to verify this observation.

Previous studies (Wang et al., 2007; Telandro, 2004; Cantu et al., 2004, 2005) report multifocal corneal ablation is safe and effective for presbyopic myopes. In the previous study (Wang et al., 2007) 10 myopes (20 eyes) with presbyopia (mean age 52 years and mean preoperative $\mathrm{SE}-4.90 \pm 2.30 \mathrm{D}$ ) were treated with multifocal LASIK. In the previous study researchers found that the postoperative UDVA ranged between 0.3-1.2, the UNVA 


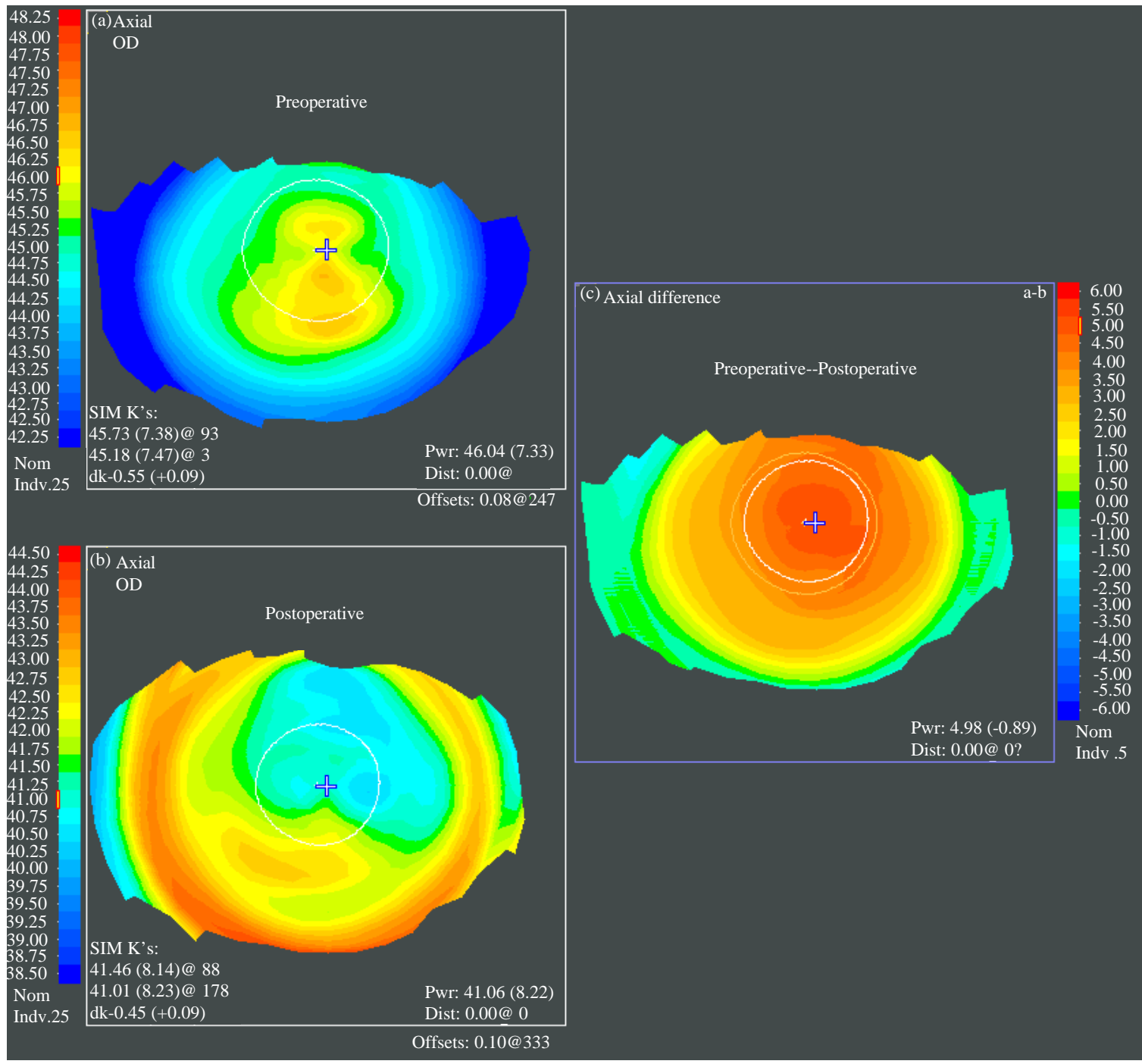

Fig. 10: Sample corneal topography preoperatively and postoperatively. The difference map indicates the difference between the preoperative and postoperative maps

ranged between $0.4-1.0,80 \%$ eyes were within $\pm 1.00 \mathrm{D}$ of intended SE and $70 \%$ subjects were satisfied with the surgery (Wang et al., 2007). The current study had better predictability and efficacy compared to our previous experience (Wang et al., 2007). This may indicate that mini-monovision peripheral presbyLASIK is advantageous over multifocal LASIK. For example, $86 \%$ of the subjects in the current study were satisfied postoperatively which is $16 \%$ higher than the previous study (Wang et al., 2007). Additionally, more demanding patients may be satisfied with the treatment strategy because target for both eyes are myopic. The outcomes from the current study compare favorably to previous investigations of presbyLASIK or LASIK induced micromonovision. Epstein and Gurgos (2009) prospectively investigated monocular peripheral presbyLASIK on the non dominant eye with monofocal correction on the dominant eye of presbyopic myopes. They reported that $20 / 20$ or better binocular UDVA was achieved by $70.7 \%$ of subjects which is similar to the outcome of $71 \%$ ((Epstein and Gurgos, 2009). Epstein and Gurgos (2009) found that $65.3 \%$ of subjects achieved $20 / 20$ or better binocular UNVA which similar to $54 \%$ reported in the current study (Table 3). In the current study, $54 \%$ of subjects achieved binocular UNVA of $20 / 20$ or better. Recent studies of LASIK for presbyopia using various ablation monovision type or presbyLASIK report $45-65 \%$ of subjects achieved UNVA of $20 / 20$ or better (Table 3). Retreatment rates ranging from 10-19\% have been reported after LASIK for presbyopia which is 
Table 3: Summary of safety, binocular distance and near uncorrected visual acuities of studies of myopic presbyopes undergoing PresbyLASIK or monovision

\begin{tabular}{|c|c|c|c|c|c|c|c|}
\hline Study & Excimer laser & $\begin{array}{l}\text { Type of presbyopic } \\
\text { ablation }\end{array}$ & $\begin{array}{l}\text { Mean preop } \\
\text { MRSE (D) }\end{array}$ & $\begin{array}{l}\text { Loss of CDVA } \\
\geq 1 \text { line }(\%)\end{array}$ & $\begin{array}{l}\text { Binocular } \\
\text { UDVA } \geq 20 / 20 \\
\end{array}$ & $\begin{array}{l}\text { Binocular } \\
\text { UNVA } \geq 20 / 20 \\
\end{array}$ & $\begin{array}{l}\text { Retreatment } \\
\text { rate }(\%)\end{array}$ \\
\hline $\begin{array}{l}\text { Current study } \\
\text { (Wang et al.,2007) }\end{array}$ & $\begin{array}{l}\text { NIDEK EC } \\
5000 \mathrm{CX} \text { II }\end{array}$ & $\begin{array}{l}\text { Mini-monovision } \\
\text { peripheral } \\
\text { presbyLASIK }\end{array}$ & $-7.05 \pm 2.00$ & 7 & $71 \%$ & $54 \%$ & 2.0 \\
\hline $\begin{array}{l}\text { Epstein and } \\
\text { Gurgos (2009) }\end{array}$ & VISX S4 & $\begin{array}{l}\text { Monocular } \\
\text { presbyLASIK }\end{array}$ & $-3.72 \pm 2.41$ & 14.6 & $70.7 \%$ & $65.3 \%$ & 16.6 \\
\hline Reinstein et al. (2011) & $\begin{array}{l}\text { Zeiss Meditec } \\
\text { MEL } 80\end{array}$ & Micro-monovision & $-4.22 \pm 1.67$ & 7.4 & $90.4 \%$ & $\begin{array}{l}89 \%(\geq 20 / 25) \\
\geq 20 / 20 \text { not reported }\end{array}$ & 19.0 \\
\hline $\begin{array}{l}\text { Gordon } \\
(2010)\end{array}$ & $\begin{array}{l}\text { Wavelight } \\
\text { Allegretto }\end{array}$ & PresbyLASIK & $\begin{array}{l}-5 \text { to }+3 \\
\text { Sphere with } \\
+3 \text { cylinder }\end{array}$ & Not reported & $75 \%$ & $45 \%$ & 10.0 \\
\hline
\end{tabular}

Preop denotes preoperative; LASIK: Laser In situ Keratomileusis; CDVA: Corrected Distance Visual Acuity; UDVA: Uncorrected Distance Visual Acuity, UNVA: Uncorrected Near Visual Acuity; MRSE: Manifest Refractive Spherical Equivalent, $\geq$ : greater than or equal to

considerably $>2 \%$ reported in the current study. However, varying criteria for performing retreatment may account for differences (Table 3) (Reinstein et al., 2011; Epstein and Gurgos, 2009; Gordon, 2010).

Monovision corrects presbyopia using the concept of unequal correction of one eye versus the other. The dominant eye is typically fully corrected for distance vision and the non-dominant eye still retains myopia between 1.25-2.50D for near vision (Cox and Krueger, 2006; Goldberg, 2003; Miranda and Krueger, 2004; Reilly et al., 2006). For subjects who can tolerate this anisometropia between eyes, there is a high degree of satisfaction. However, stereopsis decreases and $80 \%$ of monovision subjects have reported difficulty with night driving and others simply cannot tolerate monovision (Cox and Krueger, 2006; Goldberg, 2003; Miranda and Krueger, 2004; Reilly et al., 2006). In the current study, mini-monovision (or micro-monovision) reduces the anisometropia between eyes which may increase tolerance for anisometropia.

A concern with peripheral presbyLASIK is the mitigation of the near effect due to pupillary miosis. However, pseudoaccommodation occurs due to the effect of mini-monovision, the increased depth of field due to pupillary miosis and the induced spherical aberration. Hence, there are some compensatory effects to ensure the peripheral presbyLASIK profile maintain functional near vision despite pupillary miosis. In the current study, spherical aberration changed by $0.26 \mu \mathrm{m}$, becoming positive postoperatively. This similar in sign and magnitude $(0.20 \mu \mathrm{m})$ to the change reported for micromonovision by Reinstein et al. (2011). The induction of positive spherical aberration has been associated to an increase in the accommodative range and near acuity (Artola et al., 2006). In the current study, the positive spherical aberration may contribute to an improvement in the depth of field as proposed by Reinstein et al. (2011). Corneal asphericity may also contribute to increased depth of field however, the lack of data on asphericity in this study is a limitation.
In the current study, theoretically, stereopsis remains unaffected due to the small difference between eyes. However, further study is necessary to validate this observation. This mitigation of the loss of stereopsis may play a role in the high levels of subject satisfaction postoperatively. In the current study, researchers maintained $0.50 \mathrm{D}$ of anisometropia based on a pilot study. This is a markedly lower magnitude of anisometropia compared to monovision correction (Reilly et al., 2006). Additionally we selected subjects with myopia of $-4.00 \mathrm{D}$ or lower because many presbyopes with higher myopia require more than one pair of glasses for daily tasks as shown in Fig. 8. Drivers were excluded from participating in this study because the data on the effect of multifocal corneal ablation on night driving remains unclear.

As the basic mechanism of accommodation remains under study, current surgical strategies largely focus on presbyopia compensation rather than restoring accommodation. In the current study, the increase in postoperative accommodative amplitude is most likely related to the increase in postoperative pseudoaccommodation. Accommodative amplitude increased in the majority of subjects in the current study, however it still remained a function of age. Based on this observation, older presbyopes may require greater anisometropia between eyes, perhaps 1.00D for functional near vision. Hence, it is somewhat difficult for subjects to absolutely discontinue spectacle use despite minimonovision peripheral presbyLASIK. Subjects should be counseled that there is a compromise between the binocular distance vision and the binocular near vision according to their specific requirements.

\section{CONCLUSION}

The current study indicated that mini-monovision peripheral presbyLASIK is a safe, effective and highly predictable surgery for myopic patients with presbyopia but further studies are necessary to evaluate long term stability and a determine more suitable multifocal corneal ablation profile. 


\section{REFERENCES}

Alio, J.L., J.J. Chaubard, A. Caliz, E. Sala and S. Patel, 2006. Correction of presbyopia by technovision central multifocal LASIK (PresbyLASIK). J. Refract. Surg., 22: 453-460.

Artola, A., S. Patel, P. Schimchak, M.J. Ayala, J.M. Ruiz-Moreno and J.L. Alio, 2006. Evidence for delayed presbyopia after photorefractive keratectomy for myopia. Ophthalmology, 113: 735-741.

Cantu, R., M.A. Rosales, E. Tepichin, A. Curioca, V. Montes and J. Bonilla, 2004. Advanced surface ablation for presbyopia using the Nidek EC-5000 laser. J. Refract. Surg., 20: s711-713.

Cantu, R., M.A. Rosales, E. Tepichin, A. Curioca, V. Montes and J.G. Ramirez-Zavaleta, 2005. Objective quality of vision in presbyopic and non-presbyopic subjects after pseudoaccommodative advanced surface ablation. J. Refract. Surg., 21: s603-605.

Cox, C.A. and R.R. Krueger, 2006. Monovision with laser vision correction. Ophthalmol. Clin. North Am., 19: $71-75$.

Epstein, R.L. and M.A. Gurgos, 2009. Presbyopia treatment by monocular peripheral presbyLASIK. J. Refract. Surg., 25: 516-523.

Goldberg, D.B., 2003. Comparison of myopes and hyperopes after laser in situ keratomileusis monovision. J. Cataract Refract. Surg., 29: 1695-1701.
Gordon, M., 2010. Presbyopia corrections with the WaveLight ALLEGRETTO: 3-month results. J. Refract. Surg., 26: S824-826.

Mantry, S. and S. Shah, 2004. Surgical management of presbyopia. Cont. Lens. Ant. Eye, 27: 171-175.

Miranda, D. and R.R. Krueger, 2004. Monovision laser in situ keratomileusis for pre-presbyopic and presbyopic patients. J. Refract. Surg., 20: 325-328.

Ostrin, L.A. and A. Glasser, 2004. Accommodation measurements in a prepresbyopic and presbyopic population. J. Cataract Refract. Surg., 30: 1435-1444.

Reilly, C.D., W.B. Lee, L. Alvarenga, J. Caspar, F. Garcia-Ferrer and M.J. Mannis, 2006. Surgical monovision and monovision reversal in LASIK. Cornea, 25: 136-138.

Reinstein, D.Z., T.J. Archer and M. Gobbe, 2011. LASIK for Myopic Astigmatism and Presbyopia Using NonLinear Aspheric Micro-Monovision with the Carl Zeiss Meditec MEL 80 Platform. J. Refract. Surg., 27: 23-37.

Telandro, A., 2004. Pseudo-accommodative cornea: A new concept for correction of presbyopia. J. Refract. Surg., 20: s714-s717.

Telandro, A.P. and J. Steile 3rd, 2006. Presbyopia: Perspective on the reality of pseudoaccommodation with LASIK Ophthalmol. Clin. North Am., 19: 45-69.

Wang, X.X., Y.Q. Xing and R.H. Zhou, 2007. An initial observation of multifocal LASIK to correct presbyopia. Med. J. Wuhan Univ., 28: 658-660. 